\title{
7
}

\section{PLAGIARISM IN MASTER'S AND DOCTORAL STUDIES}

\section{COPING WITH THE CHALLENGES}

\section{Nonnie Botha}

\section{INTRODUCTION}

Much research has been published recently about university student plagiarism in general, focusing on specific universities in particular countries (Busch \& Bilgin 2014; De Jager \& Brown 2010; Kier 2014; Morton McKay 2014; Newton 2015; Ramzan, Munir, Siddique \& Asif 2012; Yang 2012) but limited published research exists on the complexities of plagiarism at master's and doctoral level. A study at Calicut University, Kerala, South India (Vasudevan \& Suchithra 2013) indicated that although doctoral students are aware of copyright, they are less aware of plagiarism. This observation resonates with another study which found that postgraduate students do not necessarily have "prior knowledge about academic integrity" (Mahmud \& Bretag 2013:432). Serious cases of alleged and proven plagiarism have been identified at postgraduate level from time to time at universities across the world (Ison 2014), thus highlighting that current strategies to address this issue in higher education are not as effective as we would want them to be (Ercegovac \& Richardson, 2004; Potthast, Barrón-Cedeño, Eiselt, Stein \& Rosso, 2010; Morton McKay 2014).

The above implies that universities need to consider developing more effective coping strategies relevant to postgraduate plagiarism. This chapter provides a possible point of departure towards this end, presenting some views on how plagiarism is conceptualised, the reasons for plagiarism and strategies to cope with plagiarism, all in the higher education context. These views on plagiarism have emerged from selected published scholarly literature, empirical data generated in one faculty at a South African university and relevant policy documents from selected South African universities. Five themes subsequently crystallised that could be used to 
inform strategies to cope more effectively with plagiarism in the postgraduate higher education context.

\section{WHAT THE LITERATURE REPORTS ON PLAGIARISM}

Hawley (1984, cited in Larkham \& Manns 2002:340) conceptualises plagiarism on a continuum "ranging from sloppy paraphrasing to verbatim transcription with no editing of sources". Although Price (2002) contends that plagiarism is not only difficult to define, but that it is by its very nature not definable, Park (2003:472) provides a definition that presents plagiarism as "the theft of words or ideas, beyond what would normally be regarded as general knowledge". He later adds to this definition the lack of acknowledgement (Park 2004). Conceptions of plagiarism may also differ between students and academics (East 2010). Some examples of plagiarism are handing in an essay that you did not write; copying words or ideas from someone else's work without giving credit; failing to put a quote in quotation marks; giving incorrect information about the source of a quotation; copying sentence structure but changing words around without giving credit; copying so many words or ideas from a source that it makes up the majority of your work, with or without giving credit; self-plagiarising (Bennett 2005; Ercegovac \& Richardson 2004; Park 2003; Sutherland-Smith 2005). Ison (2014:273) identifies categories of plagiarism definitions in the literature, referring to definitions indicating "a very clear division between the fair and the unethical use of text" as compared to those "with more leeway", a "variety of levels of plagiarism" and the role of intentionality, ignorance of citation methods and other abilities.

Many reasons for plagiarism are provided in the literature, such as a lack of understanding what plagiarism really means; a mismatch between student and staff understandings of plagiarism; large and/or competitive classes; collaborative learning styles; authoritarian teaching styles; certain types of assessment practices; means and opportunity; an 'everybody-does-it' attitude; peer pressure to conform; pressure to perform from community, parents, school and teachers; time pressure; laziness; non-mother tongue study and ineffective study skills (Ashworth, Bannister \& Thorne 1997; Bennett 2005; Flint, Clegg \& Macdonald 2006; Hayes \& Introna 2005; Park 2003; Price 2002). Lines (2015:1) contends that many people do not know the difference between professionally editing theses and substantive editing, which could result in plagiarism.

The literature also reports on research about the characteristics of people who plagiarise. On the one hand, plagiarism occurs more often among younger people, males and undergraduates; in countries with authoritarian cultures and where 
intellectual traditions do not frown on copying. On the other hand, it is less likely that plagiarism will happen among people with a higher skill level in academic integration; those in a sound financial situation; postgraduate students and people with good time management skills. Prevalence of plagiarism varies according to discipline (eg marketing, business and management students and students from the hard sciences are more likely to plagiarise than students from other disciplines) and personality types play a role (Ashworth et al 1997; Bennett 2005; Ercegovac \& Richardson 2004; Larkham \& Manns 2002; Park 2003; Pennycook 1996). The temptation would be to use these typical characteristics to predict the likelihood for plagiarism to occur; however, this is not encouraged.

Several strategies for limiting plagiarism are reported in the literature, detection being one of the most widely used. Plagiarism detection has much support internationally and its prominence is growing. It is interesting to note that the number of groups from all over the world who developed plagiarism detectors for the first international competition on this topic increased from 13 to 18 in the second competition (held in 2010) (Potthast et al 2010:1). Competitions such as these focus on identifying gaps in existing detectors and subsequently in improving the detectors. The abovementioned second competition, for example, revealed that existing detectors focus too much on text retrieval from local document collections while the focus should be more on Web text retrieval. Obfuscation and cross-language plagiarism were also highlighted as requiring more research in future (Potthast et al 2010) as these varieties of plagiarism would need more refined detection strategies. An example of such refinement occurs in a detection framework that focuses on coding style in writing (Arabyarmohamady, Moradi \& Asadpour 2012).

Another strategy towards limiting plagiarism is to apply holistic institutional practices, rather than piecemeal approaches. Such practices include detection tools and a formative rather than punishing approach, sound policies, awareness of paper mills, code of honour and effective education, development and enablement interventions (Macdonald \& Carroll 2006; Park 2003, 2004; Price 2002). Interesting enough, research found that warnings (verbal and written) do not work (Bennett 2005).

A third strategy towards limiting plagiarism is to develop new kinds of pedagogies with an emphasis on making a unique contribution, rather than regurgitating other people's thinking. This approach resonates well with the principle of negotiating academic identities and values in students and academics (Chandrasoma, Thompson \& Pennycook 2004; Liu 2005). Assessment strategies, as part of pedagogy, could also be harnessed against plagiarism. Such assessment strategies could include instructions and topics for assignments that require not only factual reporting, but 
rather also explain, solve problems, make decisions, link topics to student experiences; not repeatedly giving the same assignments but changing them regularly; expecting students to provide comprehensive resource lists; allowing students to rewrite papers and being careful about the nature of feedback to students (Barrett \& Malcolm 2006; Ercegovac \& Richardson 2004; Leask 2006; Price 2002; Tackett, Shaffer, Wolf \& Claypool 2012). Fataar (2012:103) indicates that research supervision, as pedagogy, "involves working with scholarship identity processes that are based on awareness of and sensitivity about the ontological dimension of doing research and not only focussing on giving students advice and instruction ...". This is relevant to the role of feedback from the supervisor as first assessor of postgraduate work.

A fourth strategy to discourage plagiarism is to educate people about paraphrasing, ethical use of information, concepts of authorship and intellectual ownership, social responsibility standards, moral development, proper referencing as well as the difference between plagiarism and a new contribution to knowledge (Devlin 2006; Landau, Druen \& Arcouri 2002; Roig 2001).

A final strategy (Bretag et al 2014:1166) is to include "three specific elements of academic integrity" in university policies, namely those of access, support and detail.

Three distinct trends emerged from the literature regarding university approaches to plagiarism. These trends could be grouped on a continuum: at the one extreme of the continuum are approaches characterised by a 'warn-detect-punish-policy'; further along the continuum are approaches that add to the latter the notions of 'education-development-enablement' (Barrett \& Malcolm 2006; Devlin 2006; Price 2002), while at the other extreme of the continuum appear the advocates of a holistic institutional approach (Bertram Gallant 2011; Davis, Drinan \& Bertram Gallant 2009; East \& Donnelly 2012; Macdonald \& Carroll 2006; Park 2004; SutherlandSmith 2008). Another study (Morton McKay 2014) found that a prevention-anddevelopment approach would be most effective if a detection-and-enforcement support system is utilised as well.

Some examples of holistic institutional approaches in the literature provide more detail about the issues to be attended to. Park (2004) presents an institutional plagiarism framework built on seven core pillars: transparency, ownership, staff and students to accept responsibility, academic integrity, compatibility between the framework and the institution's culture, prevention, deterrence, and targeting students for support and development. In their review of three institutional case studies to "illustrate possible triggers for adopting an holistic approach" Macdonald and Carroll (2006:233) concluded that eight elements are essential in a holistic approach, namely teaching academic writing skills, awareness of academic regulations on plagiarism, academic 
integrity as primary value, staff development activities, decisions to be informed by core policy and procedures, establishing a data base of plagiarism cases, maintaining accurate statistics on plagiarism occurrences, and assessment-led solutions. East and Donnelly (2012) report on a systematic approach to integrated academic integrity education at an Australian university, highlighting the use of "a suite of academic integrity resources" that consists of an academic integrity module about values for students, an academic integrity module about their responsibilities for staff, academic referencing modules for students, an academic referencing tool and an academic integrity website which provides advice, information and links to university policies and related resources (East \& Donnelly 2012:3). They stress the importance of a coordinated, systematic approach that includes all relevant parties (East \& Donnelly 2012:9). Finally, Kaposi and Dell (2012) write about discourses of plagiarism. They identify four types of discourse, namely moralist, proceduralist, developmental and intertextuality discourses, contending that all these discourses support the assumptions of suspect intention, transparency of interpretation and the homogeneous nature of the academic community. All the discourses also subscribe to the idea that student identities are either honest or dishonest and they accept the triad of prevention, detection and punishment. Kaposi and Dell further argue that a radical re-conceptualisation of plagiarism could be discovered in the discourse of intertextuality where intention, interpretation and academic community are construed as social practices relevant to the negotiation of identities and values.

\section{METHODOLOGY}

While the literature provides valuable insights into plagiarism in studies at higher education institutions across the world, very little research has been published about what postgraduate students and their supervisors have to say about this phenomenon, and even less about the South African context in this regard. This study therefore focuses on the postgraduate South African context by generating data through a case study at one faculty at a South African university and from relevant policy documents of selected South African universities.

\section{Case słudy with workshops}

The qualitative research approach was employed for the case study. Convenience sampling was used to identify the particular case, as the author was employed in that specific faculty of a South African university at the time. The case was deemed appropriate for the research as a number of serious contraventions of academic integrity at postgraduate level occurred in that faculty shortly before the data 
generation. The population for the participants was three-dimensional, namely all research supervisors, master's and doctoral students in the selected faculty at the time. Data were generated through workshops specifically designed and conducted for this purpose, one for each of the three sets of participants. The workshops were aimed at uncovering students' and supervisors' understanding of plagiarism, what they believed to be reasons for plagiarism, and how current strategies against plagiarism could be improved. The workshop facilitator was assisted by an experienced research assistant who recorded the workshop proceedings, with prior written permission from the participants. The recordings were transcribed and analysed.

Participants were recruited by inviting all members of the population to the workshops. To ensure that sufficiently rich data would be generated, it was decided that each workshop would have a minimum of 10 participants and to ensure that sharing was not inhibited by too many voices, a maximum of 20 participants per workshop. The eventual number of student participants was within this optimum range, with 19 master's students and 12 doctoral students. However, only four supervisors participated in their workshop. Participation was on a voluntary basis and this was indicated very clearly in the invitation letters. Before the data generation commenced, the required ethical clearance was obtained from the relevant faculty and university structures and official documentation to this effect is on record.

\section{Relevant university policy documents}

The relevant policy documents that were available on the websites of a selection of 10 South African universities were consulted. These 10 universities were selected to include the full range of types of South African universities, based on the following attributes: institutions that merged in 2005 under the new higher education act and those that did not; universities with high research outputs and others lower down the research spectrum; universities of technology; comprehensive universities; institutions that historically served racially segregated communities in the apartheid dispensation prior to 1994 (previous black African, 'coloured', white and Indian institutions). As the policies are public documents, confidentiality is not an issue. In line with one of the defining attributes of qualitative research, the policy review did not analyse the relevant individual policies, but rather identified the range of plagiarism facets covered in all the policies as a collective, thus constituting a point of departure for developing 'best practices' in future. The focus of the study guided the scrutiny of the policies, concentrating on how plagiarism is conceptualised, reasons for plagiarism and strategies for coping with plagiarism. 


\section{REPORTING THE FINDINGS}

\section{The workshops}

The conversations during the workshops moved spontaneously back and forth among the three main issues (understandings of plagiarism, reasons for plagiarism, and strategies to limit plagiarism); therefore it was not possible to deal consecutively and separately with each of these issues. The findings from the workshops are presented according to the main ideas that spontaneously emerged; these main ideas are indicated in italics at the start of each paragraph. The participants' own words are presented below to support the claims made; the master's students' words are identified with $M$ in brackets, the doctoral students' with $D$ and the supervisors with S.

One participant highlighted that plagiarism sometimes happens unintentionally: "... some might have plagiarised by accident, and that's when it becomes a bit grey because it wasn't done intentionally, copied and pasted and it becomes scary" (M). Another participant stated that people who plagiarise sometimes "... don't have a bad intention" (D). Some doctoral students experienced a deep fear of plagiarising unintentionally and believed that they need to be better equipped about antiplagiarism strategies to become confident that they did not plagiarise. A strategy to limit plagiarism would thus be to have awareness discussions, as this would assist students and supervisors in understanding what exactly plagiarism is. Requests for an explanation of what self-plagiarism is came from the master's students.

Supervisors indicated that the principle of acknowledging the original source of knowledge is paramount in academic writing. Not having the requisite skills to acknowledge the work of others was a challenge for postgraduate students. Better education and development of students and academics would go a long way to limit this. Participants said that "... some people do not know how to acknowledge other people for their work" (M) and "[w]e need to educate students more on plagiarism ..." (D). They need specific skills such as how to reference an email conversation (M). Suggestions were also made for a workshop on academic writing skills $(M, S)$.

Participants also emphasised that because of the focus on "saying things in your own words" (M), everybody was not necessarily equally aware that plagiarism does not only constitute using someone else's words, but also "... when someone steals someone else's idea without acknowledging them" (M) and "... they have changed the words but have not changed the idea and that is still plagiarism" (S). Plagiarism is compared to stealing "... from Eskom cables, they are called inziyonka, it is dangerous 
and some have died in the process of stealing" (D). Master's students said they need to be taught how to paraphrase in a way that would not constitute plagiarism.

Another issue with which many participants struggled was that "... there is a lot of knowledge out there that has been around for many years, so when will a new idea or specific idea become common knowledge?" (S), implying that it does not need referencing. Supervisors found it difficult to explain to students what common knowledge is.

Many participants found it challenging to separate their own ideas and life experiences from those of others and were uncertain about how to report these in an academic text, saying "... am I allowed to indicate my own experience?" (D) and students who ".... would just sort of add in pieces, drawing out of their own experience without pre-empting it by saying based on my own experience..." (S). The other side of the coin also emerged, when the question was asked why some people find it necessary to 'pump up' their writing with so much literature (S), or "... how do we know when we have referenced sufficiently?" (M).

The cultural dimension is evident in the remark that in some cultures one is not expected to critique or change the words of knowledgeable people, but rather to emulate what they have said (S). Another cultural element came to the fore when one of the participants indicated that "... knowledge was transmitted from our elders to us for generations, our grandmothers and grandfathers telling us so many stories ... but now when I am telling my children these stories, I tell them they are my stories" (M). This happens in most cultures across the world, which raises a question about the difference between individual intellectual property and collective cultural property. Another question that arose was "... can one plagiarise outside the four walls of the academic setting?" (M).

It was also acknowledged that a person who regularly plagiarises "... will not grow or develop ..." as such a person will not be able to "... serve the people around him or her with new knowledge" $(M)$; also "... the growth and development that adding to the knowledge does not happen when you plagiarise because when plagiarism happens, we are just reproducing existing stuff and repeating ..." (D). A master's student said that "... we can't come up with creative ideas when we use someone else's ideas". A participant pointed out that there is "... desecration without destruction" (D), depicting the violation plagiarism represents, also calling it "piracy" (D).

Another insight from the master's group was that some people would continue to do something wrong although they know that it is wrong. 
One of the reasons for plagiarism was given as "... not understanding the consequence of plagiarism" (M) such as being stripped of a doctoral degree that was achieved through plagiarism (D).

A strategy suggested by students towards limiting plagiarism was to be trained in using the Turnitin electronic tool with their supervisors, as this would promote their academic development (M, D). It is also believed that a writing workshop to hone their ability to develop and formulate an argument $(D, S)$, how to critically engage with the literature $(D, S)$ and how to present their own comments on the literature $(D$, S), would discourage plagiarism. Supervisors also said that "... time is a big factor", that students use short cuts to writing as they do not have sufficient time for their studies or are unable to plan and use their time efficiently.

Other strategies that would involve supervisors directly are to negotiate an agreement between students and academics about how to handle plagiarism and to have a mutually agreed upon supervisory protocol in place (M, D). They also believed that "... academics, supervisors, professors should lead by example" (M). Supervisors also see themselves as pivotal in guiding students in practical strategies to avoid plagiarism, such as advising them on using electronic detection tools, paraphrasing skills, bringing the issue of plagiarism regularly in individual and group discussions, etc. It was indicated that supervisors sometimes plagiarise from their students, which places the latter in a very difficult position (M).

Students and supervisors who must work in English but have another mother tongue, must receive special support $(M, S)$, as the "... language problem also comes into play. Sometimes we find out that if your home language is Afrikaans and you are trying to express yourself, you won't be able to as you wish" (M).

Supervisors stated that when a student "... is studying mainly for the sake of the qualification ... get a doctorate without getting the attribute of doctorateness", it could also lead to plagiarism. This kind of pressure "... could be from family members or someone else" (S).

The only notable difference between the inputs from the master's and doctoral students was that the former were grappling more with understanding plagiarism better while the latter were concerned with developing specific academic skills to combat plagiarism. The supervisors' workshops reflected their involvement with supervision strategies that would develop true doctorateness. The inputs from all individuals were clearly the result of the kinds of experience and exposure they have had in their studies, their supervision and with plagiarism issues, thus reflecting a slice of the specific issues in the South African context. 


\section{Policies}

Descriptions or definitions of plagiarism are included in all the consulted policy documents, in some cases more extensively than others. In the policy of the Cape Peninsula University of Technology (CPUT 2012:2) plagiarism is defined as "the representation of another person's ideas, research, expressions, computer code, design artefacts, or work as one's own", the Nelson Mandela Metropolitan University (NMMU 2013:2) policy defines plagiarism as "a form of academic dishonesty and means the failure to acknowledge, whether intentionally or negligently, that one has made use of someone else's work in producing what one has submitted as one's own work" and the University of Limpopo (UL 2014:3) policy notes that plagiarism is "tantamount to dishonesty and fraud aimed at misleading and misrepresenting facts". The descriptions and definitions in the consulted policies reflect what is found in the scholarly literature.

Some policies include examples of plagiarism, some more comprehensive than others (eg CPUT, NMMU, UL, UP). These examples include quoting from others' work without acknowledgement, imitating existing designs into one's own work, paraphrasing or summarising without acknowledgement, translating without citing the source, collusion, information from the Internet without proper referencing, ghost-writing and self-plagiarism. In the consulted policies specific mention is made of common knowledge and that using this is not regarded as plagiarism; it is also highlighted that poor or incomplete referencing does not constitute plagiarism.

It was interesting to note that most of the consulted policies did not refer to reasons for plagiarism; this could be because reasons are not perceived by the policymakers as essential policy or procedural issues. The few reasons for plagiarism that are included in some policies are the easy access to information from the Internet (eg NMMU), that some students come from a poor schooling system, a lack of information and awareness among students as well as a lack of referencing skills.

The collective of consulted policy documents acknowledges the complexity of plagiarism issues. These issues are managed and disciplined according to the seriousness of the infringement, which is in most instances classified in two, three or four levels or categories (eg CPUT, UJ). The few institutions that do not have level/category classifications deal with the matter as relevant to first- and secondyear students, other undergraduates and postgraduates (eg UL). Some institutions take cognisance of levels/categories of seriousness as well as undergraduate or postgraduate level (eg UJ). 
The responsibility to manage and guide is indicated in the policies as being part of the normal academic management process and lies at the door of students, academic administrators, academics, programme convenors, heads of schools and deans of faculties. Specific mention is made of the fact that different conventions may be prevalent in the various disciplines and that cognisance should be taken of these conventions. For instance, one policy requires that academic staff "should educate their students about the conventions of referencing in their discipline" (NMMU 2013:4).

All the institutions acknowledge the need for prevention (through education, creating awareness, providing information), detection (also widely mentioned in the literature), development (including remedial opportunities), and punishment (as a consequence if development does not have the envisaged outcome). Specific issues about what matters students need to be educated on are mentioned in some policies, for example induction into disciplinary conventions, training in referencing conventions and acceptable academic ways to use others' ideas. In some cases specific informative, educative and preventative mechanisms or interventions are also included. One policy mentioned lecturer training in particular (UP). It is heartening that none of the institutions approach plagiarism only from a stance of 'warn-detect-punish-policy'.

Most institutions require an undertaking of originality from students when submitting work for assessment. All institutions have some departmental, school, faculty and/ or institutional committee structure and procedure in place for following up after detection of plagiarism and once education and development about the matter have proved to be unsuccessful. One institution also provides an option of anonymous reporting of plagiarism occurrences. A student plagiarism register is also included in some policies. Only a few policies include reference to plagiarising by staff members, while some policies indicate that failure to acknowledge the source when using the ideas of others constitutes an important breach of the values and conventions of the academic enterprise (eg UJ).

\section{RECURRING VOICES FROM THE FINDINGS}

Some recurring voices can be identified from the literature, the case study and the policies that were included in this study. These voices could be construed as important themes to inform institutional strategies towards coping more effectively with the challenges of plagiarism at postgraduate level. The relevant themes are presented below. 


\section{From an orientation of "detect-and-punish" to a 'holistic institutional approach"}

The first theme is to move away from focusing only on warnings, detection, complying with policy and punishment. Both the literature and the workshops indicated that there is a need for more than this: it is desirable to add to the 'warn-detect-policypunish' dimension also a dimension of 'education-development-enablement' as well as doing all this under the umbrella of a holistic institutional approach.

In many South African universities most aspects of the 'warn-detect-policy-punish' dimension are already in place, as reflected in their policies. These aspects need refinement and further development as required over time. Many students and academics have become aware of and have started implementing some ad hoc forms of the 'education-development-enablement' dimension. This dimension needs more focus in line with institutional policy; furthermore, details regarding what and how to implement should be devolved to faculty/school/departmental levels.

The third dimension, namely to have an institutional framework, also needs to be considered by universities and further developed according to the relevant policy. Such an institutional framework could gain from the insights reflected in the literature regarding a coordinated, systematic approach employing academic integrity resources (East \& Donnelly 2012), the seven pillars of Park's framework (2004) and the essential elements of a holistic institutional approach put forward by Macdonald and Carroll (2006).

\section{Focus on negotiation of academic values and academic identities}

In the literature referred to previously in this chapter, it is argued that plagiarism could be reconceptualised through the discourse of intertextuality where intention, interpretation and academic community are construed as social practices relevant to the negotiation of identities and values (Kaposi \& Dell 2012) which should be understood to include authorship and ownership (Pennycook 1996). One of the university policies mentioned before resonates well with this viewpoint, when it contends that failure to acknowledge the use of ideas of others constitutes an important breach of the values and conventions of the academic enterprise. Developing academic values and academic identities is therefore crucial in coping more effectively with the challenges of plagiarism, especially at postgraduate level (not excluding undergraduates), as it is at postgraduate level that universities play a pivotal role in developing intellectuals, researchers and academics. 


\section{Establish developmental interventions}

While the first two themes are embedded mainly in the overall institutional level, the effectiveness of the final three themes is likely to be enhanced if devolved to faculty level and lower. Some of the consulted university policies venture into providing for specific developmental interventions; however, it is not always appropriate to have a 'one-size-fits-all' approach prescribed by policy (see also Macdonald \& Carroll 2006). Consultation should take place regularly with students and academics to determine specific needs, and developmental interventions should subsequently be tailored accordingly. The workshop participants in this study, who were all postgraduate students or supervisors, clearly indicated that they or their students need such developmental interventions, including improving their understanding of plagiarism, support to identify their new contribution in research and assignments, how to critically engage with the literature, how to develop an argument and support it from the literature, empowerment to own the electronic plagiarism detection strategy in use at their institution, and support to develop appropriate time management strategies within their individual academic contexts. The particular interventions are likely to differ from one academic year to the next, as the needs of each postgraduate cohort might differ from the previous one. Funding should be earmarked by institutions to identify needs and implement interventions, while faculties/schools/departments should be responsible for implementation, including planning these into the time schedules and workloads of students and academics.

\section{The principle of changing pedagogies (including formative assessment-led solutions)}

The fourth theme relates to changing pedagogies, including formative assessmentled solutions. Examples are described in the literature section above and should be tailored to the context of each discipline and programme level. Supervisors are likely to need some support in developing skills to effectively conceptualise and implement pedagogies that would equip them and their students in coping more successfully with plagiarism.

\section{Include academics and students in all initiatives}

The workshop participants in this study firmly indicated that both postgraduate students and supervisors need support in this matter; this key idea in the literature (East \& Donnelly 2012; Macdonald \& Carroll 2006; O'Connor 2014; Park 2004) is also reflected in the policies. Both students and supervisors should thus be included in all initiatives, from developing an institutional framework through to implementing 
developmental interventions. The appropriateness of involving students and supervisors either parallel with each other, jointly or consecutively, should also be carefully considered and negotiated in advance with the relevant parties.

\section{SUMMARY, RECOMMENDATIONS FOR FURTHER RESEARCH AND CONCLUSION}

This chapter identified recurring voices that could serve to inform institutional strategies towards coping more effectively with the challenges of plagiarism at postgraduate level. The themes emerged from selected literature on plagiarism, plagiarism policies of 10 selected South African universities and empirical data from three data-generating workshops conducted in one faculty of a South African university: one with master's students, one with doctoral students and one with postgraduate research supervisors.

Some limitations were inherent in the research and selection of source material. The poor participation in the workshop by the supervisors is a limitation of the research; it was addressed by a feedback-and-discussion session on the outcomes of the three workshops with all academics in the faculty, including research supervisors. Although the attendance at this session was excellent, no additional data emerged from the discussions. Another limitation is that policies from only 10 South African universities were consulted, as it is possible that other policies would have enhanced the research findings. Also, if a sample of relevant policies from international universities were consulted, richer insights are likely to have emerged.

Finally, further research that would add value to the insights that came from this study could include the following:

- a wider sample of policy documents from universities in South Africa and internationally (see also the work done by Bretag 2013)

- a similar research initiative at a larger sample of South African and international universities

- more in-depth information about country-wide academic integrity initiatives elsewhere

- merging all of the above-mentioned to culminate in an overall framework and implementation plan that would serve the international postgraduate context

In conclusion: although plagiarism is unlikely to disappear from the postgraduate context in higher education, institutions need to review their strategies regularly to cope more effectively with this matter. Should institutions take cognisance of the themes identified in this study when conducting such reviews, it would make 
a positive contribution towards promoting academic values and enhancing the academic enterprise.

\section{REFERENCES}

Arabyarmohamady S, Moradi H \& Asadpour M. 2012. A coding style-based plagiarism detection. Paper presented at an international conference on Interactive Mobile and Computer Aided Learning, November 2012, Amman, Jordan.

Ashworth P, Bannister P \& Thorne P. 1997. Guilty on whose eyes? University students' perceptions of cheating and plagiarism in academic work and assessment. Studies in Higher Education, 22(2): 187-203.

Barrett R \& Malcolm J. 2006. Embedding plagiarism education in the assessment process. International Journal for Educational Integrity, 2(1):38-45.

Bennett R. 2005. Factors associated with student plagiarism in a post-1992 university. Assessment \& Evaluation in Higher Education, 30(2):137-162.

Bertram Gallant T. 2011 . Creating the ethical academy: A systems approach to understanding misconduct and empowering change in higher education. New York: Routledge.

Bretag T. 2013. Exemplary academic integrity project: Lessons for Australia, Europe and beyond. Keynote address: Plagiarism across Europe and beyond conference, 12-13 June 2013.

Bretag T, Mahmud S, Wallace M, Walker R, McGowan U, East J, Green M, Partridge L \& James C. 2014. 'Teach us how to do it properly!' An Australian academic integrity student survey. Studies in Higher Education, 39(7):1150-1169.

Busch P \& Bilgin A. 2014. Student and staff understanding and reaction: Academic integrity in an Australian university. Journal of Academic Ethics, 12(3):227-243.

Chandrasoma R, Thompson C, \& Pennycook A. 2004. Beyond plagiarism: Transgressive and non-transgressive intertextuality. Journal of Language, Identity, and Education, 3(3):171193.

CPUT (Cape Peninsula University of Technology). 2012. Policy on plagiarism. Cape Town: Cape Peninsula University of Technology.

Davis SF, Drinan PF \& Bertram Gallant T. 2009. Cheating in school: What we know and what we can do. Hoboken, NJ: Wiley Blackwell.

De Jager K \& Brown C. 2010. The tangled web: Investigating academics' views of plagiarism at the University of Cape Town. Studies in Higher Education, 35(5):513-528.

Devlin M. 2006. Policy, preparation, and prevention: Proactive minimization of student plagiarism. Journal of Higher Education Policy and Management, 28(1):45-58.

East J. 2010. Judging plagiarism: A problem of morality and convention. Higher Education, 59(1):69-83.

East L \& Donnelly L. 2012. Taking responsibility for academic integrity: A collaborative teaching and learning design. Journal of University Teaching \& Learning Practice, 9(3). [Retrieved 15 October 2015] http//ro.vow.edu.au/jutlp/vol9/iss3/2 


\section{PART TWO • INSTITUTIONAL MEASURES FOR POSTGRADUATE STUDENT SUCCESS}

Ercegovac Z \& Richardson JV. 2004. Academic dishonesty, plagiarism included, in the digital age: A literature review. College \& Research Libraries, July: 301-318.

Fataar A ed. 2012. Debating thesis supervision: perspectives from a university education department. Stellenbosch: SUN MeDIA Stellebosch.

Flint A, Clegg S \& Macdonald R. 2006. Exploring staff perceptions of student plagiarism. Journal of Further and Higher Education, 30(2):145-156.

Hayes N \& Introna LD. 2005. Cultural values, plagiarism, and fairness: When plagiarism gets in the way of learning. Ethics \& Behavior, 15(3):213-231.

Ison DC. 2014. Does the online environment promote plagiarism? A comparative study of dissertations from brick-and-mortar versus online institutions. Journal of Online Learning and Teaching, 10(2):272-281.

Kaposi D \& Dell P. 2012. Discourses of plagiarism: Moralist, proceduralist, developmental and inter-textual approaches. British Journal of Sociology of Education, 33(6):813-830.

Kier CA. 2014. How well do Canadian distance education students understand plagiarism? The International Review of Research in Open and Distance Learning, 15(1):227-248.

Landau JD, Druen PB \& Arcouri JA. 2002. Methods for helping students avoid plagiarism. Teaching of Psychology, 29(2):112-115.

Larkham PJ \& Manns S. 2002. Plagiarism and its treatment in higher education. Journal of Further and Higher Education, 26(4):339-349.

Leask B. 2006. Plagiarism, cultural diversity and metaphor - implications for academic staff development. Assessment \& Evaluation in Higher Education, 31 (2): 183-199.

Lines L. 2015. Substantive editing as a form of plagiarism among postgraduate students in Australia. Assessment \& Evaluation in Higher Education. [Retrieved 15 October 2015] http://doi:10.1080/02602938.2015.1013019

Liu D. 2005. Plagiarism in ESOL students: Is cultural conditioning truly the major culprit? ELT Journal, 59:234-241.

Macdonald R \& Carroll J. 2006. Plagiarism - a complex issue requiring a holistic institutional approach. Assessment \& Evaluation in Higher Education, 31 (1):233-245.

Mahmud S \& Bretag T. 2013. Postgraduate research students and academic integrity: 'It's about good research training'. Journal of Higher Education Policy and Management, 35(4):432-443.

Morton McKay T. 2014. Combatting plagiarism using a community of practice approach. South African Journal of Higher Education, 28(4):1315-1331.

Newton P. 2015. Academic integrity: A quantitative study of confidence and understanding in students at the start of their higher education. Assessment \& Evaluation in Higher Education. [Retrieved 15 October 2015] http://dx.doi.org/10.1080/02602938.2015.10 24199

NMMU (Nelson Mandela Metropolitan University). 2013. Policy for the promotion of academic integrity and prevention of plagiarism. IRC 305.04. Port Elizabeth: Nelson Mandela Metropolitan University. 
O'Connor Z. 2014. Extreme plagiarism: The rise of the e-idiot? The International Journal of Learning in Higher Education, 22(1):1-11.

Park C. 2003. In other (people's) words: Plagiarism by university students - literature and lessons. Assessment \& Evaluation in Higher Education, 28(5):471-488.

Park C. 2004. Rebels without a clause: Towards an institutional framework for dealing with plagiarism by students. Journal of Further and Higher Education, 28(3):291-306.

Pennycook A. 1996. Borrowing others' words: Text ownership, memory, and plagiarism. TESOL Quarterly, 30(2):201-230.

Potthast M, Barrón-Cedeño A, Eiselt A, Stein B \& Rosso P. 2010. Overview of the 2nd international competition on plagiarism detection. Notebook Papers of CLEF 2010 LABs and Workshops, 22-23 September, Padua, Italy.

Price M. 2002. Beyond "Gotcha!": Situating plagiarism in policy and pedagogy. College Composition and Communication, 54(1):88-115.

Ramzan M, Munir MA, Siddique N \& Asif M. 2012. Awareness about plagiarism among university students in Pakistan. Higher Education, 64(1):73-84.

Roig M. 2001. Plagiarism and paraphrasing criteria of college and university professors. Ethics \& Behavior, 11 (3):307-323.

Sutherland-Smith W. 2005. Pandora's box: Academic perceptions of student plagiarism in writing. Journal of English for Academic Purposes, 4:83-95.

Sutherland-Smith W. 2008. Plagiarism, the internet and student learning: Improving academic integrity. Abingdon: Routledge.

Tackett J, Shaffer R, Wolf F \& Claypool G. 2012. Student plagiarism and economic versus moral based pedagogy. Journal of Business and Accounting, 5(1):136-149.

UJ (University of Johannesburg). 2013. Policy: Student plagiarism. 5P/5.4. University of Johannesburg. Education. [Retrieved 13 January 2016] http://www.uj.ac.za/about/ Documents/policies

UL (University of Limpopo). 2014. Plagiarism policy. University of Limpopo. [Retrieved 13 January 2016] http://www.ul.ac.za/application/downloads/PLAGIARISM\%20\%20POLICY

UP (University of Pretoria). 2009. Plagiarism prevention policy. S 4729/09. University of Pretoria. [Retrieved 13 January 2016] http://www.up.ac.za/media/shared/409/ZP_Files/ s4726_09plagiarism-prevention-policy.zp62477pdf

Vasudevan TM \& Suchithra KM. 2013. Copyright awareness of doctoral students in Calicut University Campus. International Journal of Digital Library Services, 3(4):94-1 10.

Yang SH. 2012. Attitudes and behaviors related to academic dishonesty: A survey of Taiwanese graduate students. Ethics \& Behavior, 22(3):218-237. 